Ciência e Natura, Santa Maria v.38 n.2, 2016, Mai.- Ago. p. 920 -931

Revista do Centro de Ciências Naturais e Exatas - UFSM

ISSN impressa: 0100-8307 ISSN on-line: 2179-460X

\title{
CIÊNCIA'NATURA
}

\section{Logística reversa: um estudo de caso em empresas do setor madeireiro na fronteira oeste do Rio Grande do Sul - RS}

\author{
The state of reverse logistics in some municipalities and border campaign of the \\ west Rio Grande do Sul/ RS \\ Caroline Dutra Ochôa e Andressa Rocha Lhamby \\ Universidade Federal do Pampa \\ caroline_ochoa@hotmail.com; andressalhamby@hotmail.com
}

\begin{abstract}
Resumo
A logística reversa torna possivel o retorno dos residuos da indústria madeireira ao ciclo produtivo. A gestão dos resíduos da matériaprima madeira é uma necessidade para a maioria dos municipios da fronteira oeste do Rio Grande do Sul (RS), podendo com a sua ausência ou inadequação promover a degradação ambiental através do desperdício do recurso natural. Este trabalho busca ampliar o conhecimento sobre a situação da logística reversa dos produtos da indústria madeireira em dois municípios da fronteira oeste do Rio Grande do Sul. Com relação à metodologia, utilizou-se um estudo de caso, caracterizado pela natureza descritiva e exploratória. As técnicas de coleta de dados foram através de questionários, respondidos pelos gestores das empresas nas cidades de Bagé e São Gabriel. Os principais resultados encontrados foram: as empresas analisadas possuem total desconhecimento da Lei $n^{o} 12.305$ que instituiu a Política Nacional de Resíduos Sólidos e a principal utilização desses resíduos de madeira, são como maravalha e serragem. O estudo aponta que a maior dificuldade está no desconhecimento dos responsáveis elou proprietários das empresas em relação à logística reversa. A logística reversa é capaz de fazer uma revalorização dos resíduos de pós-consumo, aumentando a competitividade das empresas e diminuindo a quantidade de resíduos.
\end{abstract}

Palavras-chave: Logística Reversa, resíduos sólidos, Política Nacional dos Resíduos Sólidos, setor madereiro.

\begin{abstract}
Reverse logistics makes possible the return of waste from the timber industry to the production cycle. Waste management of the raw material wood is a necessity for most municipalities in the western border of Rio Grande do Sul (RS), may by his absence or inadequacy promote environmental degradation through the natural resource waste. This paper seeks to expand knowledge on the state of reverse logistics of the timber industry products in two municipalities of the western border of Rio Grande do Sul. With respect to methodology, we used a case study, characterized by descriptive and exploratory nature. The data collection techniques were through questionnaires answered by the managers of companies in the cities of Bagé and Sao Gabriel. The main results were analyzed companies have total ignorance of Law No. 12,305 which established the National Policy on Solid Waste and the main use of such wood waste, wood shavings and sawdust are like. The study shows that the greatest difficulty is the lack of responsible and / or owners of companies with respect to the reverse logistics. Reverse logistics is able to make a revaluation of post-consumer waste, increasing business competitiveness and reducing the amount of waste.
\end{abstract}

Keywords: Reverse logistics, solid waste National Policy of Solid Waste, lumberjack sector. 


\section{Introdução}

A sustentabilidade e práticas de responsabilidade socioambiental têm se tornado um assunto cada vez mais oportuno, visto que a sociedade e as organizações estão atuando em prol da minimização de problemas relacionados ao meio ambiente humano. Nesse contexto, a logística reversa caracteriza-se como uma importante ferramenta para que as empresas possam alcançar as metas de sustentabilidade econômica, social e ambiental. Este tema é de extremo valor, visto que, através de determinadas práticas, é possível se avançar em qualquer setor de mercado, respeitando o meio ambiente.

Segundo LEFF (2000) os desequilíbrios ecológicos em escala planetária e os processos de degradação ambiental decorrem do desenvolvimento progressivo das forças produtivas e (destrutivas), guiadas pelo objetivo de maximizar os lucros nas economias capitalistas, e os excedentes nas economias socialistas.

Atualmente, alguns fatores, como por exemplo: o desenvolvimento tecnológico, as mudanças de padrões de comportamento dos consumidores e o avanço nas legislações ambientais levaram as empresas a repensar seus processos produtivos e de negócios. A globalização ultrapassou obstáculos e barreiras de acesso à informação, tornando possível a melhoria de velhos conceitos, sendo estes, substituídos por novas técnicas gerenciais.

Entretanto, para Donaire (1999), a questão ambiental nas empresas envolve: produtos obtidos de matérias-primas renováveis ou recicláveis, que não agridam o meio ambiente e com baixo consumo de energia no processo. Procedimentos com poluição controlada, mínima geração de resíduos, baixo risco para os trabalhadores, pouco consumo de energia e eficiência na utilização dos recursos. A conscientização ambiental dispõe do objetivo de ser mais competitiva; gerando novas oportunidades; comprometimento gerencial; capacitação do pessoal, treinamento em todos os níveis e capacidade de desenvolver produtos ecologicamente corretos.

Andrade, Ferreira e Santos destacam que os principais fatores que motivam as empresas a implementar a logística reversa são: legislação, razões competitivas, melhoria da imagem coorporativa, revalorização econômica, renovação de estoques, ganhos econômicos, responsabilidade sócio-ambiental, recuperação de ativos e/ou de valor, e prestação de serviços diferenciados.

Sobre isto Marchi (2011) comenta que as estratégias empresariais de proteção ambiental e de logística reversa entre as empresas brasileiras são crescentes, seja para se tornarem empresas ambientalmente sustentáveis como para evitar 
penalidades e sanções previstas pela legislação ambiental vigente.

$$
\text { Diante disso, o presente estudo }
$$
concentra esforços para identificar e analisar um estudo sobre a logística reversa em empresas do setor madeireiro na fronteira oeste do RS.

\subsection{Logistica Reversa}

Ao longo dos anos, houve grande evolução tanto na logística quanto na logística reversa. Pode-se adotar, dentro da empresa moderna, uma definição de logística mais atual, a qual foi sugerida por CSCMP (2012), que apresenta a logística como um importante processo, que visa planejar, implementar e controlar, da maneira mais eficiente possível, o fluxo e também a armazenagem dos produtos. A logística reversa também implementa e controla os serviços e informações associadas, estendendo desde o ponto de origem até o ponto do consumidor, tendo como principal objetivo o atendimento das necessidades daquele consumidor.

A logística reversa pode ser entendida como um processo complementar à logística tradicional, pois enquanto a última tem o papel de levar produtos dos fornecedores até os clientes intermediários ou finais, a logística reversa deve completar o ciclo, trazendo de volta os produtos já utilizados dos diferentes pontos de consumo a sua origem (LACERDA, 2002). Nesse mesmo sentido, Mueller (2005) também comenta que a logística reversa e a logística convencional apresentam processos semelhantes, entretanto a logística reversa deveria ter papel de destaque dentro das organizações, pois tratase de uma ferramenta que, se bem aplicada, confere maior lucratividade empresarial.

Como o termo "Logística Reversa" ainda é novidade no mundo empresarial, se torna importante definir essa atividade. Na visão de Leite (2009), a logística reversa compreende a movimentação e destinação adequada de materiais de pós-consumo e de pós-venda que surgem nos processos industriais e comerciais. Esses materiais, denominados de resíduos, se reintegram, novamente, ao processo produtivo, podendo agregar valor para a empresa. Por meio dos canais de distribuição reversos, o valor é agregado de diversas formas, sendo eles, de valor econômico, ecológico, de imagem corporativa, entre outros. De acordo com a Política Nacional de Resíduos Sólidos (PNRS, Lei $\mathrm{n}^{\circ}$ 12.305/2010), a logística reversa é entendida como:

Instrumento de desenvolvimento econômico e social caracterizado por um conjunto de ações, procedimentos e meios destinados a viabilizar a coleta e a restituição dos resíduos sólidos ao setor empresarial, para reaproveitamento, em seu ciclo ou em outros ciclos produtivos, ou outra destinação final ambientalmente adequada.

Segundo Ministério do Meio Ambiente (2012), um dos objetivos fundamentais estabelecidos pela Política Nacional dos Resíduos Sólidos é a obrigatoriedade da sua implementação. Devem ser priorizadas a não geração de resíduos, redução, reutilização, reciclagem, tratamento dos resíduos sólidos e disposição final ambientalmente adequada dos rejeitos. Da mesma forma, a Revista CREA (2011), corrobora com essa ideia e diz que com a lei da PNRS, os fabricantes, importadores, distribuidores, comerciantes, consumidores e titulares do serviço de limpeza urbano, devem criar uma rede de coleta e distribuição desses materiais para que todos tenham a sua destinação correta.

Em relação à legislação na logística reversa, o Decreto $n^{\circ} 7.404 / 2010$ criou entre outros, o Comitê Orientador para a Implantação dos Sistemas de Logística Reversa. O artigo 13 do referido decreto determina:

A logística reversa é o instrumento de desenvolvimento econômico e social caracterizado pelo conjunto de ações, procedimentos e meios destinados a viabilizar a coleta e a restituição dos 
resíduos sólidos ao setor empresarial, para reaproveitamento, em seu ciclo ou em outros ciclos produtivos, ou outra destinação final ambientalmente adequada.

De acordo com a PNRS Lei $n^{\circ} 12305 / 2010$ são obrigados a estruturar e implementar sistemas de logística reversa, mediante retorno dos produtos após o uso pelo consumidor, os fabricantes, importadores, distribuidores e comerciantes de: agrotóxicos, pilhas e baterias, pneus, lâmpadas fluorescentes, produtos eletroeletrônicos, entre outros.

Adotando-se essas e outras medidas, as organizações poderão realizar uma redução nos custos, cumprir a legislação, desempenhar papel importante na defesa pelo meio ambiente e ainda melhorar sua imagem perante a sociedade.

Segundo o pensamento de Leite (2003) é necessário saber onde a logística reversa é aplicada, ou seja, em quais atividades as empresas e indústrias podem e devem utilizar essa ferramenta com o objetivo de gerar um diferencial competitivo sustentável. São de duas formas basicamente: Produtos de Pós-Venda e Produtos de Pós-Consumo. É chamada "Logística Reversa de Pós-venda" a área responsável pela administração de informações e fluxo físico de bens que devido ao pouco uso, ou ao desuso, voltam à cadeia de distribuição direta (ZIMERMANN; GRAEML, 2003). Como exemplo, pode-se citar aparelhos eletrônicos com defeito. Em contra partida, o pós-consumo trata da gestão da informação e fluxo de físico de bens que chegaram ao final de sua vida útil ou, em ultimo caso, foram parcialmente utilizados, porém permitem reutilização, como embalagens e metais (ZIMERMANN; GRAEML, 2003). A Figura 1 representa as duas áreas de atuação da logística reversa que, conforme Leite (2003) podem ser consideradas independentes, mas diferenciadas pelo estágio ou fase do ciclo de vida útil do produto retornado.

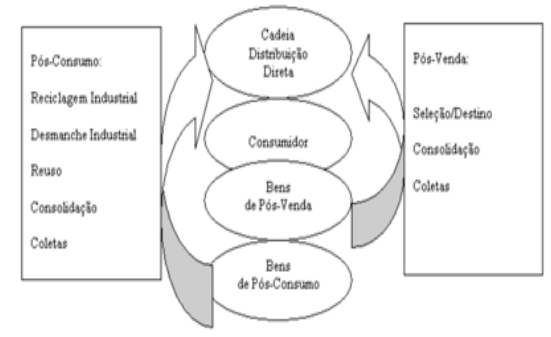

Figura 1: Área de atuação e etapas reversas

Fonte: Leite (2003)

A relevância do uso da logística reversa se dá por diversos motivos. As legislações ambientais atuais se tornaram mais rígidas, o maior comprometimento com o meio ambiente e o quanto este será impactado. Com isso, foi possível criar uma imagem mais positiva nas organizações e do mesmo modo, os fabricantes, não se preocupam com o produto apenas durante o processo produtivo, mas pelo acompanhamento dele até o final de sua vida útil. Aumentou-se, portanto, o número de negócios, gerando mais empregos e serviços e criando uma cultura na sociedade em relação ao desenvolvimento sustentável.

Leite (2009) analisando ganhos de competitividade no retorno dos produtos de pósconsumo indica que a logística reversa quando eficiente consegue fazer com que a organização reaproveite os componentes e os materiais constituintes, através de uma eficiente montagem da rede reversa. Coletando e suprindo os produtos de retorno às linhas de desmanche, distribuindo os produtos e componentes remanufaturados nos mercados secundários e apoiando o processo 
industrial. A organização obterá ganhos competitivos no que diz respeito aos custos operacionais, devido às economias na elaboração dos produtos, além de melhorar sua imagem corporativa.

\subsection{Indústria Madereira}

O Brasil possui uma grande cobertura florestal, uma das maiores do mundo, perdendo apenas para a Rússia. O Ministério do Meio Ambiente estima que $69 \%$ dessa cobertura tenham potencial produtivo e em função disso, o país desenvolveu uma estrutura produtiva complexa no setor florestal, e relações com produtores de equipamentos, insumos, projetos de engenharia e empresas de produtos florestais (SNIF, 2015).

Estima-se que o Setor Florestal seja responsável por 3,5\% do Produto Interno Bruto (PIB de 2007) do Brasil, equivalente a US\$ 37,3 bilhões, e 7,3\% das exportações totais, significando US\$ 10,3 bilhões (SNIF, 2015).

Buainain e Batalha (2007) complementam que em função dos ativos florestais e da capacidade industrial, o Brasil vem ampliando a participação na produção e no comércio mundial. Nosso país reúne condições excelentes no setor florestal, quando analisados os aspectos de custo e diferenciação de produto, tecnologias de melhoramento genético e manejo florestal, que trazem vantagens competitivas para o país. No entanto, esta tendência é desafiada pelas crescentes dificuldades que as empresas enfrentam de ampliar seus negócios, especialmente na região amazônica.

Para a Confederação Nacional da Indústria (2012) a pouca infraestrutura econômica, a política tributária, a regulação de comando e controle, e a fragilidade social dificultam a produção em escala e a competição nos mercados nacional e internacional.
Segundo o governo do estado do Rio Grande do Sul, a indústria de madeira, celulose e móveis gaúchos são destaque nacional, respondendo por $15 \%$ de toda a produção brasileira. O setor é responsável por 4\% do PIB gaúcho e fatura mais de R\$ 8 bilhões por ano, com marcante aspecto social, emprega, direta e indiretamente, cerca de 300 mil pessoas.

\subsection{Cadeira Produtiva da Madeira e a geração de resíduos}

Cadeia produtiva é um conjunto de etapas consecutivas nas quais fluem os produtos transformados e transferidos os diversos insumos desde a pré-produção até o consumo final de um bem ou serviço. (SNIF, 2010).

Em concordância com Selmany (1993), o sistema produtivo da madeira reúne as atividades relacionadas a ela e aos seus derivados. É caracterizado pelo conjunto de atividades que garantem a produção, da colheita à transformação da madeira até o estágio onde esta última, por associação de seus derivados a outras matérias, perde a característica de constituinte essencial do produto.

De acordo com a Confederação Nacional da Indústria (2012, p. 15) “A cadeia produtiva da indústria de manejo sustentável de florestas naturais tem como recurso natural as florestas naturais, as quais são aproveitadas sustentavelmente."

O Fluxograma Cadeia Produtiva da madeira seguir representa a cadeia produtiva da madeira, segundo SNIF (2015):

Segundo Pozl et al. (2013) a cadeia produtiva da madeira é composta basicamente por três cadeias: cadeia produtiva da madeira industrial, que é composta por papel, painéis de alta densidade, aglomerados, MediumDensityFibreboard (MDF) e OrientedStrandBoard (OSB); cadeia produtiva da madeira para energia, formada por lenha e carvão; e cadeia produtiva do processamento mecânico composta por serrados, compensados e laminados. 


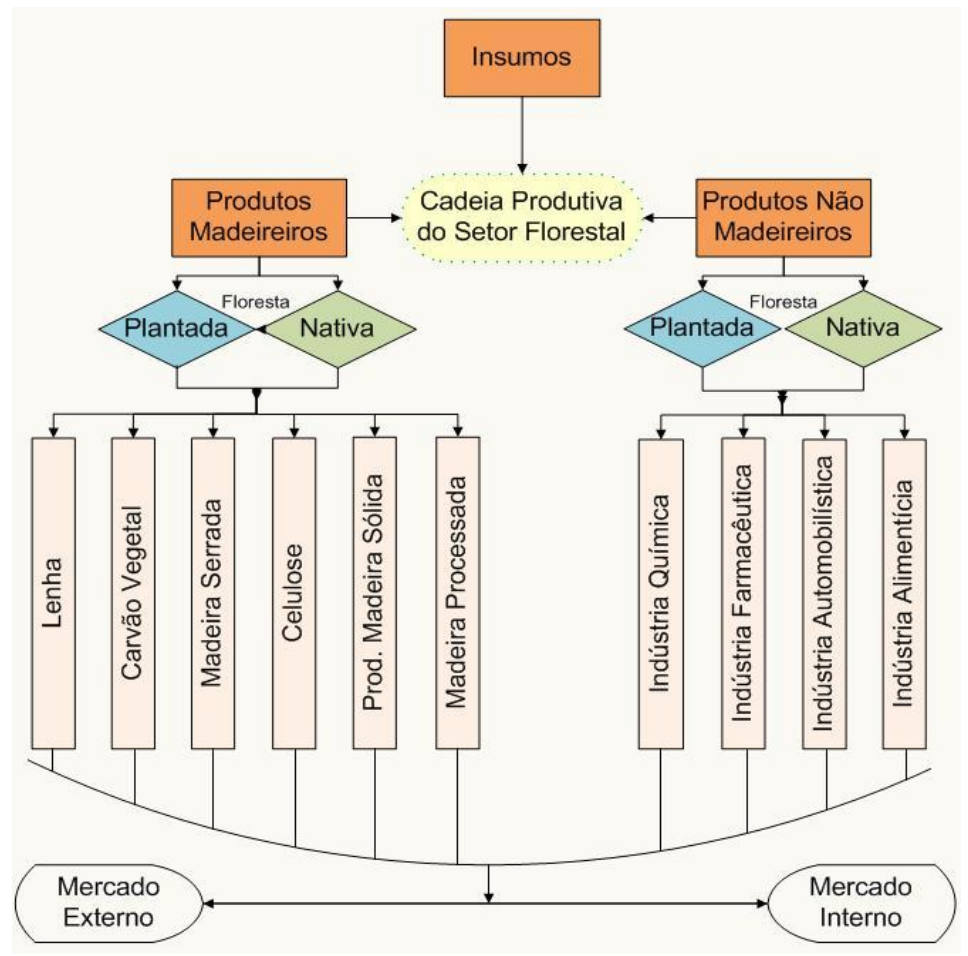

Figura 2: Fluxograma Cadeia Produtiva da madeira Fonte: SNIF (2015).

Buainain e Batalha (2007) consideram a indústria de madeira sólida, madeira serrada, painéis compensados e laminados, painéis de madeira, indústria de móveis, celulose, papel e papelão, como os principais mercados de produtos florestais.

\section{De acordo com}

Roque \& Valença (1998), a indústria de base florestal pode ser dividida conforme o produto final obtido que pode ser: lenha, postes, madeira serrada, lâminas de madeira, painéis colados, compensados, aglomerados, chapas duras de fibras, chapas de fibras de média densidade, celulose e papel. Desses produtos, a madeira serrada e os painéis de madeira são alguns insumos da cadeia produtiva de madeira e móveis, os quais, por processos de usinagem, geram resíduos sólidos em várias etapas da cadeia.

O volume de resíduos gerados no processamento de toras de madeira pode ser expresso como a diferença entre o volume de madeira em toras que entra na serraria e o volume de madeira serrada produzida. A maior quantidade de resíduos é gerada quando do desdobro das toras estimando-se em $50 \%$ do volume total processado (JARA, 1987). Conforme Fagundes (2003), o volume de resíduos gerados poderá estar associado aos seguintes fatores: falta de qualidade da matéria prima florestal a ser processada; mudança geométrica do produto; ausência de medidas de proteção às toras; adoção de técnicas menos apuradas de desdobro, liberações de tensões durante o desdobro, escolha incorreta das ferramentas de corte; adoção de velocidade de corte incorreta; espessura do corte das serras; decisões equivocadas dos operadores da serra de desdobro e secagem inadequada da madeira serrada.

Portanto, é gerada uma quantidade muito grande de resíduos após a fabricação dos vários tipos de produtos. A seguir, o observa-se o quadro com os resíduos gerados em cada tipo de atividade onde a madeira é utilizada como matéria-prima. 
Quadro 1: Atividades geradoras de resíduos e tipos de resíduos gerados

\begin{tabular}{|l|l|}
\hline \multicolumn{1}{|c|}{ Atividade geradora } & \multicolumn{1}{c|}{ Tipos de resíduos gerados } \\
\hline Serraçōes de madeira & Serradura, serrim, aparas e cascas \\
\hline Produtos semi-elaborados da madeira & Serradura, lascas, aparase e cascas \\
\hline Produtos da cortiça & $\begin{array}{l}\text { Pedaços de má qualidade, pós de cortiça e } \\
\text { cortica negrara }\end{array}$ \\
\hline Fabricação de móveis de madeira & Serradura, serrime aparas \\
\hline Fabricaçao de peças torneadas, moldes e outros & Serradura e serrim \\
\hline Fabricação de pasta de papel & $\begin{array}{l}\text { Cascas, serradura, bóias de depuração e águas } \\
\text { negras }\end{array}$ \\
\hline
\end{tabular}

Fonte: Adaptado de APE.NA (2005)

Uma vez gerados os resíduos, como prima para outras indústrias, ou ainda para apresentado no Quadro 1, é necessária a sua destinação, que pode ser feita através da venda ao subprodutos. Destacam-se a seguir algumas destinações:

mercado secundário ou utilizados como matéria

Quadro 2: Tipos de resíduos e suas aplicações

\begin{tabular}{|c|c|}
\hline TIPOSDE RESIDUOS & DESTINACÇAOAPLICAÇĀOO \\
\hline $\begin{array}{l}\text { Serradura, aparass, cascas, ramos } \\
\text { caidos e refugos }\end{array}$ & 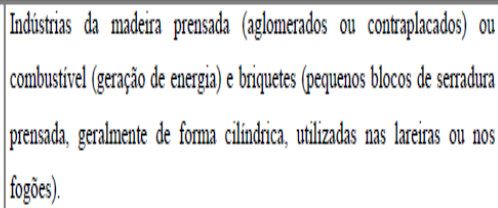 \\
\hline Cascas & Jardinagem. \\
\hline Apraras & $\begin{array}{l}\text { Camas de animais, por exemplo, em arviarios forra-se o chão com aparas de } \\
\text { maderara para reter a unidade. }\end{array}$ \\
\hline Efluentes liquidos e lama & Fabricação de biogás. \\
\hline
\end{tabular}

Fonte: Adaptado de APE.NA (2005)

Em conformidade com a Revista da Madeira (2015) o aumento da eficiência do processo industrial da madeira, também teria efeito direto na quantidade da área florestada necessária para manter os atuais níveis de produção. Por exemplo, apenas 35\% de cada tora são transformados em produto serrado, mas essa eficiência poderia ser aumentada para 55\% através de melhoramento simples na manutenção de máquinas e no treinamento de mão-de-obra.

De acordo com estes dados, $65 \%$ das toras são desperdiçadas, transformando-se em resíduos não aproveitados pela indústria. A legislação brasileira aponta a auto-responsabilidade das empresas na remoção, estocagem e tratamento de resíduos gerados pelos processos de produção, a partir de procedimentos adequados para a conservação do meio ambiente.

Fagundes (2003) sugere duas possibilidades com relação as sobras e resíduos da madeira na indústria madeireira. A primeira opção é através da melhoria no aproveitamento da matéria-prima madeira, através de medidas de redução de sobras e utilizando melhores técnicas, equipamentos e processos. A segunda opção é um correto gerenciamento dos resíduos gerados, que devido ao volume significativo, passam a ser tratadas como um ou outro produto dentro da serraria, portanto, ao invés de serem descartados, passam a ser estudados como material com diferentes opções de uso. 
Portanto, utilizar a madeira de forma mais racional, com o reaproveitamento da matéria-prima através de medidas de redução de sobras, melhores técnicas, equipamentos e processos e o investimento em logística reversa além de evitar o desperdício do recurso natural também implica na redução do impacto ambiental gerado por essa atividade.

\subsection{Vantagem Competitiva}

Devido às mudanças do cenário global, manter a competitividade está cada vez mais difícil. Os diferenciais são necessários para manter a liderança do mercado ou permanecer nele, seja qual for a necessidade. Assim, a logística reversa vem agregando vantagens para as organizações, sejam elas em relação as vantagens econômicas, ou estratégias de marketing da empresa.

O conceito de vantagem competitiva, desenvolvido por Porter (1989), procura mostrar a forma como a estratégia seguida pela organização, pode determinar e sustentar o seu sucesso competitivo. O mesmo autor destaca que o fato do desempenho acima da média em uma empresa ser lançado e sustentado por uma estratégia competitiva, pode estar em qualquer uma de suas áreas funcionais. Ela tem por objetivo atingir a eficácia operacional e, portanto, obter um desempenho de atividades melhor que de suas concorrentes.

Barney e Hesterly (2007) afirmam que, vantagem competitiva é quando a empresa é capaz de gerar maior valor econômico do que as empresas rivais. A vantagem competitiva pode derivar tanto de recursos e competências únicas da empresa específica como da exploração de uma posição específica e protegida da estrutura de mercado (COOL, COSTA E DIERICKX, 2002 apud STOECKL, 2009).

Segundo LEITE (2009, p.21), atualmente as preocupações relativas ao tree bottom line, onde estão contidos os aspectos econômicos, sociais e ambientais, tem mudado suas realidades no sentindo de que as preocupações relativas à responsabilidade empresarial e ética ambiental e social sejam o alicerce necessário para a garantia da sustentabilidade econômica.

As empresas precisam estar inseridas na busca por inovações e assim gerar vantagens competitivas no seu processo produtivo, para que possam gerar valor econômico, e consequentemente, a sua viabilidade mercadológica. Ela surge do valor do que os clientes estão dispostos a pagar pelo produto ou serviço, que uma determinada empresa consegue criar para os seus clientes e que ultrapassa os custos de produção. Isto significa que, as empresas necessitam permanentemente da diferenciação no mercado, por meio de estratégias deliberadas, visando a obtenção de vantagens competitivas que proporcionem lucros de monopólio, mesmo que temporários. (NETO, 2008)

Para Porter (1989) a estratégia competitiva é a busca de uma posição competitiva favorável, o lugar fundamental onde ocorre a concorrência. Visa estabelecer uma posição lucrativa e sustentável contra as forças que determinam a concorrência no mercado.

Vantagem Competitiva ou Diferencial Competitivo é uma ou um conjunto de características que permite a uma empresa ser diferente por entregar mais valor sob ponto de vista dos clientes, diferenciando-se da concorrência e, por isso, obtendo vantagem no mercado (GASPAR, 2001 apud STOECKL, 2009).

Em conformidade com Menegatti (apud Andrade et al., 2000), uma empresa que tem como perspectiva o modelo trade-off e disponha de outras prioridades competitivas, como o baixo custo, em detrimento a questão da preservação ambiental, desconsidera alguns aspectos de elevada importância: Não conflito entre a lucratividade e a questão ambiental; $\mathrm{O}$ movimento ambientalista cresce em escala mundial; Clientes e comunidades em geral 
passam a valorizar cada vez mais a proteção ao meio ambiente; A demanda e o faturamento das empresas passam a sofrer cada vez mais pressões, além de depender diretamente do comportamento de consumidores que enfatizarão suas preferências por produtos e organizações ecologicamente corretas.

Portanto, uma empresa que possui vantagem competitiva, é aquela que oferece um serviço ou produto único ou diferente para seus clientes, que os levam a comprar dessa empresa em detrimento de seus concorrentes. Ter uma vantagem competitiva é ter um diferencial.

\section{Materiais e Métodos}

A presente pesquisa foi realizada em três empresas madeireiras de pequeno porte, em duas cidades situadas na região da fronteira oeste do estado do Rio Grande do Sul, São Gabriel e Bagé. A pesquisa caracteriza-se como exploratória, por proporcionar, segundo Gil (1998, p.45), “maior familiaridade com o problema, com vistas a torná-lo mais explícito”, com uma abordagem metodológica de predominância qualitativa, descritiva, utilizandose de questionários enviados aos responsáveis pelas empresas.

O questionário foi elaborado a partir da pesquisa com levantamento bibliográfico, dando destaque aos trabalhos já publicados, como por exemplo, livros e artigos científicos. Foi composto por questões fechadas relacionadas com os tipos de resíduos gerados e suas quantidades, se havia algum sistema de coleta seletiva para esse material, qual a destinação, a respeito da existência de políticas de logística reversa na empresa e no município onde estão situadas, entre outros aspectos pertinentes para a pesquisa. A análise e tratamento dos dados foram apoiados qualitativamente e apresentados através de linguagem discursiva.

\section{Resultados e Discussão}

Nas empresas estudadas, os resíduos gerados são formados pelo processamento das toras de madeira transformadas em madeira serrada. Deste processo sobram resíduos principalmente de maravalha e serragem.

O responsável pela empresa A afirma que são gerados na empresa resíduos de maravalha que são designados para cama de cavalos e aviários, sendo que o restante é destinado para queima em uma usina termelétrica local.

Geram aproximadamente $30 \%$ da matéria prima consumida, que se transforma em subproduto e realizam relatórios de destinação dos resíduos a cada seis meses para a Secretaria de Ambiente e Desenvolvimento Sustentável do Rio Grande do Sul (SEMA). Até este momento, ignora-se a Lei da PNRS $n^{\circ} 12.305 / 2010$, e apesar de não conhecer a logística reversa, declara-se que a mesma é onerosa.

$\mathrm{Na}$ empresa $\mathrm{B}$, o responsável afirma que produz maravalha e serragem como resíduos de madeira e ocupa-se esse material dentro da própria organização. O restante, faz-se doações para a utilização em camas de aviários e adubação de hortaliças de pequenos produtores locais. Não possui uma estimativa da quantidade de resíduos gerados e desconhece a Lei da PNRS $\mathrm{n}^{\mathrm{o}} 12.305 / 2010$ e a logística reversa, também possui conhecimento se o município tem alguma política a respeito. Possui certificação da SEMA.

A empresa C similarmente, produz como resíduos maravalha e serragem, não tendo estimativa da quantidade de geração do material e não ocorre reaproveitamento dentro da empresa, fazem doações para a utilização em camas de aviários e adubação de hortaliças de pequenos produtores locais. Não compreende a Lei da PNRS $n^{\circ} 12.305 / 2010$ e da logística reversa, nem se o município dispõe de tal política. Mesmo que, possua a certificação da SEMA.

\section{Conclusões}


Através da pesquisa realizada, foi possível analisar o conhecimento das empresas madeireira com relação a logística reversa em duas cidades da fronteira oeste do Rio Grande do Sul.

A logística reversa ainda é uma área pouco conhecida e com baixa prioridade nas empresas em pesquisa. A falta de conhecimento e de visão empreendedora faz com que não haja esforços para garantir que o ciclo de logística reversa se conclua e perdem-se oportunidades de aumentar receitas e diferenciar-se no mercado.

$\mathrm{Na}$ investigação, percebeu-se que todas as organizações entrevistadas possuem total desconhecimento da Lei da PNRS $n^{\circ} 12.305 / 2010$ e que as organizações $\mathrm{C}$ e $\mathrm{B}$ não conhecem a política de logística reversa.

Em países com um grau maior de conhecimento e valorização de seus produtos, o consumo oriundo de um fluxo reverso é tão valorizado quanto o do fluxo direto. Para alcançarmos esse nível, deve-se promover ações que incentivem o consumo desses produtos. Outro aspecto importante seria a penalização adequada das contravenções nas diversas áreas envolvidas com o retorno de produtos, principalmente na área de pósconsumo, pois permitiria a atuação de empresas que tem tido uma conduta mais comprometida com negócios de retorno de bens em geral, alterando assim o mercado e abrindo novas oportunidades.

Destaca-se nesse estudo também a falta de conhecimento técnico específico para a área, dos que são responsáveis pela gestão das organizações. Acaba-se retraindo o desenvolvimento do setor e sacrificando o potencial desses resíduos, que poderiam agregar valor econômico, com possibilidade de reintegração dos resíduos ao processo produtivo.

As três empresas estudadas, encaminham esses resíduos da madeira a terceiros, para camas de animais e adubação de hortaliças, fazendo o processo de logística reversa, mesmo com o desconhecimento sobre o assunto. Utilizam de uma forma convencional ao empresário. Portanto, tem importância estratégica, e ainda é válida a prática destas destinações.

No entanto, vale ressaltar que o importante neste caso, seria a conscientização do descarte de forma correta, que não prejudique ou altere o meio ambiente e também o conhecimento de leis, destinos alternativos para cumprimento da legislação em vigor.

\section{Referências}

ANDRADE, E. M.; FERREIRA, A.C.; SANTOS, F. C. A. Tipologia de sistemas de logística reversa baseada nos processos de recuperação de valor. In: SIMPÓSIO DE ADIMINISTRAÇÃO DA PRODUÇÃO. LOGÍSTICA E OPERAÇÕES INTERNACIONAIS,12., 2009. Anais... São Paulo: FGV:EAESP, 2009.

APE.NA - Associação de profisssionais de educação do norte Alentejo. (Projeto Floresta.com). [Internet] Os resíduos de madeira. Available from: http://www.apena.rcts.pt/

BATALHA, Mário Otávio; BUAINAIN, Antônio Márcio. Cadeias produtivas de flores e mel. Brasília: IICA: MAPA/SPA, 2007.

BARNEY, Jay B.; HESTERLY, William S. Administração Estratégica e Vantagem Competitiva. São Paulo: Pearson Prentice Hall, 2007.

BRASIL. Lei $\mathrm{n}^{\mathrm{o}} 12.305 / 2010$. Institui a Política Nacional de Resíduos Sólidos; altera a Lei no 9.605, de 12 de fevereiro de 1998; e dá outras providências. Available from: $<$ http://www.mma.gov.br/port/conama/legiabre.cfm? codlegi $=636>$

BRASIL. Decreto $n^{\circ} 7.404 / 2010$. Regulamenta a Lei no 12.305, de 2 de agosto de 2010, que institui a Política Nacional de Resíduos Sólidos, cria o Comitê Interministerial da Política Nacional de Resíduos Sólidos e o Comitê Orientador para a Implantação dos Sistemas de Logística Reversa, e dá outras providências. Available from: $<$ http://www.planalto.gov.br/ccivil_03/_Ato20072010/2010/Decreto/D7404.htm>.

CSCMP. Council of Supply Chain Management Professionals. [Internet] Available from $<$ http://www.cscmp.org/>. 
CONFEDERAÇÃO NACIONAL DA INDÚSTRIA. Meio Ambiente, Brasil, 2015. Available from : http://admin.cni.org.br/portal/data/pages/FF80808137 9A7BEB0137BDBC309064FD.htm. Acesso em: agosto de 2015 .

DONAIRE, Denis. Gestão Ambiental na Empresa. São Paulo: Atlas, 1999.

FAGUNDES, H. A. V. Diagnóstico da produção de madeira serrada e geração de resíduos do processamento de madeira de florestas plantadas no Rio Grande Do Sul. 2003. 61 f. Dissertação (Mestrado em Engenharia Civil) - Universidade Federal do Rio Grande do Sul, Porto Alegre, 2003.

JARA, E. R. A geração de resíduos pelas serrarias. São Paulo, Boletim Técnico ABPM, n. 59, 1987.

LACERDA, L. Logística Reversa - Uma Visão sobre os Conceitos Básicos e as Práticas Operacionais Centro de Estudos em Logística, COPPEAD, UFRJ, 2002. Available from: < http://www.cel.coppead.ufrj.br/fs-public.htm>

LEITE, P.R. Canais de Distribuição Reversos. Revista Tecnologística. São Paulo, 2000.

LEITE, P. R. Logística Reversa: meio ambiente e competitividade. São Paulo: Prentice Hall, 2003.

LEITE, P. R. Logística Reversa: meio ambiente e competitividade. 2 ed. São Paulo: Prentice Hall Brasil, 2009.

MARCHI, C. M. D. F. Cenário mundial dos resíduos sólidos e o comportamento corporativo brasileiro frente à logística reversa. Perspectivas em Gestão \& Conhecimento, João Pessoa, v. 1, n. 2, p. 118-135, jul./dez. 2011.

MINISTÉRIO DO MEIO AMBIENTE E ICLEI BRASIL. Planos de gestão de resíduos sólidos: manual de orientação. Brasília, 2012. Available from: $<$ http://www.mma.gov.br/cidadessustentaveis/residuos-perigosos/logisticareversa>Acesso em: agosto de 2015 .

MUELLER, C. F. Logística Reversa Meio Ambiente e Produtividade. Santa Catarina: UFSC, 2005.
Available

from: http://www.empresaresponsavel.com/aulas/logistica texto_meioambiente.pdf. Acesso em: julho 2015.

NETO, José Chavaglia. Energia Solar: Uma Vantagem Competitiva. (2008). Available from: http:/www.artigonal.com/gestao-artigos/energiasolar-uma-vantagem-competitiva471535. html Acessado em: 20 de abril de 2010, 23:25

PORTER, Michael. Vantagem Competitiva: Criando e sustentando um desempenho superior. Rio de Janeiro: Campus, 1989.

POZL, W. B. et al. Cadeia produtiva do processamento mecânico da madeira - segmento da madeira serrada no estado do Paraná. In: CONGRESSO FLORESTAL BRASILEIRO, 8, 2003, São Paulo. Anais... São Paulo: SBS/SBEF, 2003. 1 CD-ROM.

REVISTA CREA. [Internet] Available from: $<$ http://www.crea-

rs.org.br/site/arquivo/revistas/ed85_truth.pdf. $>$ Acess o em: setembro, 2015.

REVISTA DA MADEIRA. [Internet] Available from:

http://www.remade.com.br/br/revistadamadeira_mate ria.php?num $=1626 \&$ subject $=$ Res $\%$ EDduos\&title $=A p$ roveitamento $\% 20$ econ $\% \mathrm{~F} 4 \mathrm{mico} \% 20 \mathrm{dos} \% 20 \mathrm{res} \% \mathrm{ED}$ duos\%20de\%20madeira> Acesso em: julho, 2015.

ROQUE, C. A. L., VALENÇA, A. C. V. Painéis de Madeira Aglomerada. BNDES Setorial. 1998. Available from: $<$ http://www.bndes.gov.br/conhecimento/bnset/set80 5.pdf $>$. Acesso: julho de 2015.

SISTEMA NACIONAL DE INFORMAÇÕES FLORESTAIS. Produção florestal, Cadeia produtiva. [Internet] Brasil, 2015. Available from: < http://www.florestal.gov.br/snif/producaoflorestal/cadeia-produtiva $>$ Acesso em: setembro, 2015.

SELMANY, Y.. Analyse Des Flux Physique De Bois À L'interieur De La Filiére-Bois. Nancy. ENGREF. 1993. 200 p. Tese. Doutorado. 
STOECKL, Karl. Conceitos de Vantagem Competitiva, sua Aplicação e Sustentabilidade (2009) Available from: $<\mathrm{http}: / /$ pt.shvoong.com/business-management/ entrepreneurship/ 1932497-conceitos-vantagemcompetitiva-sua-aplica $\% \mathrm{C} 3 \% \mathrm{~A} 7 \% \mathrm{C} 3 \% \mathrm{~A} 3 \mathrm{o} />$ Acessado em: 18 de Outubro de 2015, 16:15.

ZIMERMANN, R. A.; GRAEML, A. R. Logística reversa: conceitos e componentes do sistema. Estudo de caso: Teletex Computadores e Sistemas. XXII ENEGEP. Ouro Preto: Out. 2003. 